\title{
Resenha
}

\section{A Ecologia Política sob um olhar geográfico}

\author{
Luciano Zanetti Pessôa Candiotto
}

Ambientes e territórios: Uma introdução a Ecologia Política, Marcelo Lopes de Souza. Rio de Janeiro, Bertrand Brasil, 2019, 350 pp., ISBN 978-85-286-2437-3.

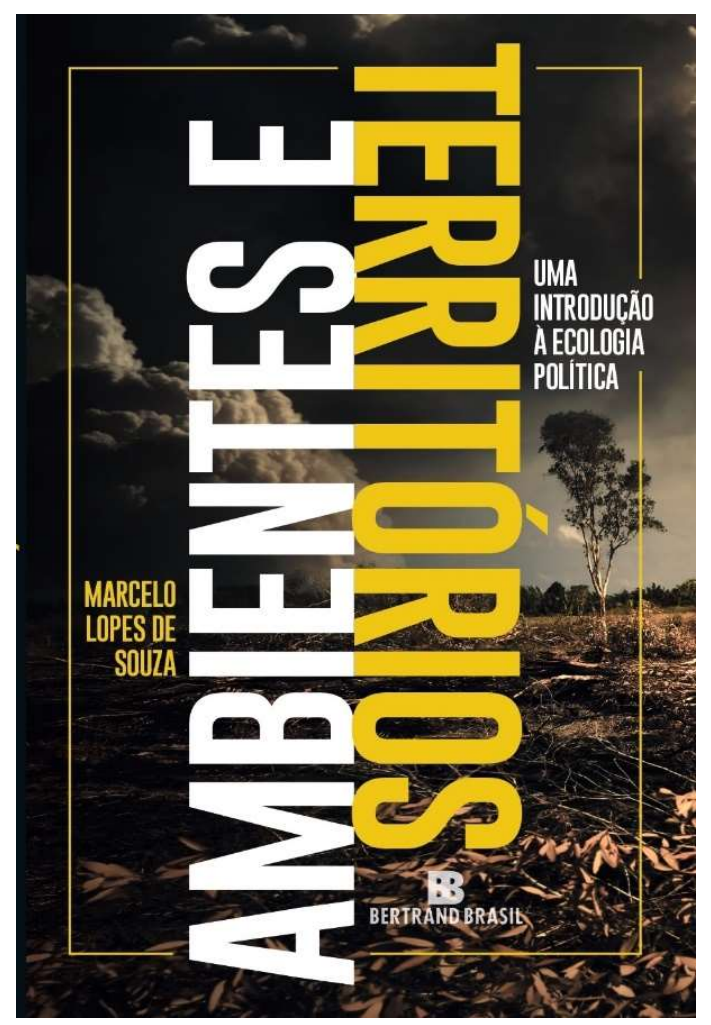

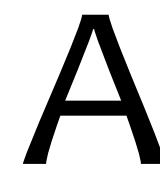
pesar de seu denso e reconhecido trabalho científico dentro da Geografia, sobretudo nos estudos urbanos, Marcelo Lopes de Souza decidiu, já há um certo tempo, ampliar o escopo de suas preocupações, transitando do "direito à cidade" para 
algo mais abrangente: em suas próprias palavras, o "direito ao planeta". Retornando, de certo modo, às suas origens intelectuais, como discípulo assumido de Orlando Valverde, Souza vem se propondo, de forma sistemática, a incorporar criticamente uma dimensão ecológica em suas pesquisas, refletindo sobre a relação sociedade-natureza a partir de uma perspectiva integradora. Sabendo da relevância da Ecologia Política para os estudos geográficos (e vice-versa), ele escreveu o livro Ambientes e territórios: uma introdução a Ecologia Política, recentemente publicado, o qual se propõe a dialogar com temas e conceitos fundamentais para geógrafos e outros interessados na Ecologia Política.

Utilizando como conceitos centrais ambiente e território, o livro é dedicado ao campo de estudos interdisciplinar (ou potencialmente transdisciplinar) da Ecologia Política. Direcionado a geógrafos e outros profissionais vinculados à pesquisa sócio-espacial, trata-se de uma obra atual e de suma importância para o entendimento de princípios da Ecologia Política, assim como para o avanço do enfoque da Geografia Ambiental no Brasil (ver, sobre isso, SOUZA, 2019a).

Com o rigor teórico e conceitual que lhe é peculiar, o autor inicia o livro defendendo um olhar anticolonial e pluralista sobre a Ecologia Política. Ao estabelecer ressalvas a uma interpretação que exagera ao localizar as raízes da Ecologia Política na Economia Política, fundamentada no marxismo e em uma leitura que prioriza a dimensão econômica da sociedade, Souza identifica elementos que atestam o reducionismo dessa perspectiva e apresenta outras possibilidades de inspiração e lastreamento teóricos a respeito dos princípios da Ecologia Política que considerem, de maneira mais equilibrada, a cultura (valores, imaginários, representações sociais) e as relações de poder (especialmente enquanto territorialidades), sem contudo, recair em qualquer culturalismo e sem negligenciar os aspectos econômicos. A crítica do marxismo, aliás, leva o autor a resgatar a contribuição pioneira de Murray Bookchin e sua social ecology, geralmente esquecida.

Outra questão discutida diz respeito a uma crítica ao preconceito segundo o qual a teorização - no âmbito da Ecologia Política e de outros campos do conhecimento - é algo feito, acima de tudo, por intelectuais de países do Norte Global, cabendo aos pesquisadores do Sul Global, tipicamente, a realização de estudos empíricos. Essa colonialidade do saber, lamentavelmente ainda hoje reproduzida até mesmo por intelectuais de esquerda da Europa e dos EUA (e não raro aceita por nós!), é muito bem problematizada, 
sobretudo, quando são discutidos os conceitos de "solo ideológico" e "atmosfera biográfica" (pp. 29-30), introduzidos pelo autor, com a ajuda dos quais ele mostra as contradições que surgem quanto a isso (e que ele explorou com maior detalhe em Souza, 2019b).

O rechaço a interpretações binárias e dualistas, principalmente nos casos da relação entre "sociedade" e "natureza", entre teoria e práxis, entre conhecimento científico e saberes populares, entre antropocentrismo e eco ou biocentrismo, entre global e local, entre urbano e rural, entre uma ênfase exagerada na ciência e na tecnologia em contraste com a romântica ideia de uma "volta à natureza" ou "ao campo" - eis outra marca do pensamento e da obra de Marcelo Lopes de Souza. A valorização de hibridismos, de perspectivas integradoras e de diálogos entre saberes, com base na "lógica dos magmas" de Cornelius Castoriadis e no pensamento complexo advogado por Edgar Morin, permitem ao leitor refletir sobre a consideração de indeterminações e incompletudes nos conhecimentos gerados para dar conta da "crise ambiental" e de outros desafios, contribuindo para a superação de uma razão dualista e de defesas míopes ou enviesadas de determinadas concepções filosóficas, políticas e éticas. Como a Ecologia Política e a
Geografia Ambiental pressupõem interações entre profissionais que produzem e se nutrem de conhecimentos sobre a natureza e sobre a sociedade, as disputas de narrativas deveriam dar lugar a um diálogo tenso, sim, porém construtivo e profícuo, como ressalta e defende Marcelo Lopes de Souza.

Além da introdução e da conclusão, Ambientes e territórios: Uma introdução a Ecologia Política possui sete capítulos. No primeiro (e mais extenso), os conceitos de ambiente e território são abordados. Ao entender $o$ ambiente terrestre enquanto a "Terra como morada humana", são discutidas similitudes entre o conceito de ambiente e o de espaço geográfico; é justificada a problematização do autor em relação à noção de "meio ambiente" (por ser, costumeiramente, associado à natureza primeira e, assim, deixar de considerar a dimensão humana e social); e é enfatizado que nós, seres humanos, também somos parte do ambiente e modificamos constantemente esse ambiente, através de uma relação metabólica e dialética que estabelecemos com a natureza. A própria percepção sobre o que é a natureza e o ambiente estão envoltas ao plano sociocultural, de modo que a visão que temos sobre esses conceitos é socialmente construída. Assim, o ambiente não é somente um envoltório. O ambiente somos também nós, histórica e 
culturalmente situados, como salienta o autor.

O conceito de território é valorizado como sendo não menos central no contexto da Ecologia Política, haja vista que, se os usos, as formas de apropriação e as lutas e conflitos ambientais compõem o cerne da Ecologia Política, não é possível tratar essas questões sem se remeter às relações de poder, que se dão nas mais variadas escalas geográficas, uma vez que “[...] o território nos guia para o domínio das relações entre espaço e poder" ( $p$. 38).

O capítulo 2 versa, especificamente, sobre as origens e princípios da Ecologia Política. No tocante às origens, são elencados tanto autores que foram pioneiros no uso do termo na década de 1970 (Wolf, Enzensberger e Gorz), quanto aqueles que, mesmo não tendo empregado a expressão, contribuíram para a tarefa de politizar a leitura das relações entre natureza e sociedade. É aqui que Souza destaca o papel de Murray Bookchin, ou, mais remotamente, o do geógrafo Elisée Reclus, sem deixar de recordar pioneiros latino-americanos como Orlando Valverde. Entre os princípios e características básicas da Ecologia Política, destacam-se os seguintes: 1) é um campo de conhecimento que busca promover um diálogo entre o saber acadêmico e o saber popular derivado de experiências de resistência e conflito; 2) ela tem sido construída com base em uma pluralidade de visões de mundo, com destaque para o marxismo mas, também, para o anarquismo (ou, mais amplamente, a perspectiva libertária), sendo um ponto em comum entre essas concepções o seu conteúdo socialmente crítico; 3) a Ecologia Política tem um compromisso com a denúncia de injustiças, recusando-se a se identificar como um conhecimento axiologicamente neutro, ou seja, sem valores. Coerente com sua crítica ao colonialismo, Souza dá destaque à produção intelectual no Brasil e na América Latina (termo de origem colonial que, aliás, também é problematizado no livro). Nos últimos anos, as publicações dedicadas à Ecologia Política têm sido ampliadas, fato amplamente demonstrado pela publicação da coletânea em dois volumes, organizada por Alimonda, Pérez e Martín (2017a e 2017b).

A (in)justiça ambiental é o tema do capítulo 3, onde são discutidos elementos como a origem do movimento por justiça ambiental nos Estados Unidos; o racismo e o classismo ambientais; a pertinência de se ampliar o escopo da ideia de justiça ambiental e a urgência de se criticar a noção falaciosa de "desastre natural"; e a relação entre os conceitos de perigo, risco, vulnerabilidade social, sofrimento ambiental e conflito ambiental. Todos esses assuntos são articulados em torno do conceito de 
justiça ambiental, ao qual Souza atribui grande importância tanto intelectual quanto prático-política.

Segundo o autor, o capítulo 4, intitulado "Impactos e conflitos ambientais", possui uma natureza teórico-metodológica, e sobretudo metodológica. Ao discutir os limites da avaliação de impactos ambientais, manifestada no Brasil através dos Estudos de Impacto Ambiental (EIA) e dos Relatórios de Impacto Ambiental (RIMA), são levantados questionamentos sobre a qualidade e a eficácia desses documentos. Também são apresentadas algumas ferramentas que podem lidar com o aspecto social dos impactos, considerando-se as relações de poder, ganhadores e perdedores. Através da proposta de utilização de matrizes e tabelas de cunho qualitativo (as matrizes e tabelas têm sido ferramentas muito comuns nas metodologias de avaliação de impactos ambientais, porém, predominam os dados quantitativos em detrimento dos qualitativos e, geralmente, falta integrar as informações do meio físico, biológico e social de uma forma não tecnicista ou escamoteadora de contradições sociais), o autor alerta para a importância de se apreender objetivos conflitantes, relações de poder, agentes, custos e benefícios de determinada ação ou empreendimento - sem nunca perder de vista os ganhadores e os perdedores. A complexidade envolta nas escalas de ação e nas práticas espaciais também é abordada, assim como a diferenciação entre conflitos estruturais e conjunturais. Por fim, a ideia de "consenso", tão em voga, é problematizada e questionada.

O capítulo 5 é dedicado aos ativismos e movimentos sociais, onde esses dois conceitos são discutidos e diferenciados. Os ativismos são considerados mais abrangentes, de modo que abarcariam os movimentos. Uma ênfase é dada aos movimentos emancipatórios, apesar de movimentos sociais também poderem ser conservadores. A heterogeneidade de ativismos e movimentos ambientais - que se reflete nas numerosas formas de ambientalismo e/ou ecologismo deriva do fato de que os ativismos se acham permeados por concepções variadas (do antropocentrismo ao ecocentrismo e ao biocentrismo, bem como pelas noções de preservação e conservação ambientais). Tudo isso é discutido no capítulo, o qual, apesar de sintético, não sonega a complexidade do emaranhado de significados e interpretações.

Dois temas vinculados a retóricas atuais no tratamento do ambiente neste século XXI são alvo do capítulo 6: a governamentalização da natureza e a securitização do ambiente. Logo no início, o autor destaca o processo de cooptação de líderes comunitários por parte do 
Estado, utilizando o exemplo dos "ecolimites" na cidade do Rio de Janeiro. Os discursos da "proteção da natureza", do "bem comum" e dos "interesse coletivos", muito utilizados no processo de governamentalização da natureza, são tratados de forma crítica e lúcida, fundamentando o debate realizado a respeito de uma "ecogeopolítica", que se dá em diferentes escalas espaciais, para além da tradicional Geopolítica, costumeiramente vista como sendo de âmbito nacional e internacional. $O$ "conservacionismo gentrificador" (termo/conceito da lavra do próprio Marcelo Lopes de Souza) e o "ecofacismo" (termo introduzido por Michel Bosquet e Murray Bookchin), são outros temas discutidos nesse capítulo.

Ao estabelecer sérias ressalvas à tese da "urbanização completa da sociedade" e à bandeira do "direito à cidade", ambas da autoria de Henri Lefebvre, o capítulo 7 é dedicado à defesa do "direito ao planeta", enfoque sobre o qual o autor já publicou vários artigos e capítulos (ver, p.ex., SOUZA, 2015 e 2019c). A premissa de uma hegemonia ideológica do urbano ("urbanofilia" acrítica) é problematizada, mas também o são as visões ingênuas e simplistas que exaltam o passado précapitalista (romanticamente visto como social e ecologicamente melhor) e cultivam uma exagerada e às vezes contraditória ojeriza à tecnologia e à ciência (ou a quase qualquer coisa que seja "ocidental"). Além da crítica das teorias de Lefebvre, consideradas eurocêntricas, e da incorporação desse olhar por intelectuais do Sul Global, o autor dialoga com as análises e propostas de Murray Bookchin ("urbanização sem cidades", "municipalismo libertário" etc.), e apresenta ainda algumas ideias do ativista e intelectual anarquista Ricardo Flores Magón. Para Souza, o grande desafio é retomar a tarefa de refletir sobre projetos de sociedade radicais, em que se saiba jogar, dialeticamente, com uma denúncia do imaginário e do modelo social capitalista (incluídas, aí, as forças produtivas e a organização espacial) e com uma recusa em abraçar soluções socialmente regressivas, como as da Deep Ecology e congêneres.

No arremate do livro, o autor ressalta que ainda há uma imensidão político-teórica a ser explorada pela Ecologia Política, deixando claro que sua orientação em relação a ela enfatiza a injustiça ambiental e a busca de uma práxis emancipatória. Buscando ser fiel a alguns trechos das conclusões do livro, cabe uma citação literal, que sintetiza a visão do autor sobre a Ecologia Política. A vocação desta seria, para ele, "[...] a denúncia do poder e do saber heterônomos que atravessam e influenciam os vínculos entre os seres humanos e o espaço 
geográfico, daí partindo para divisar alternativas" (p. 309).

Vale, igualmente, citar o trecho em que Souza, meditando sobre a superação necessária do dualismo na análise dos vínculos entre "sociedade" e "natureza", realimentado pela razão instrumental e pelo imaginário capitalista ocidental, grifa que ela “(...) há de se dar, nos marcos dos hibridismos culturais, sociais e civilizatórios que experimentamos quase todos nós, em níveis e de modos diferentes, por meio de uma criação de novas concepções e significações imaginárias sociais, no bojo da edificação de novas práticas sociais e espaciais, novas formas de sociabilidade e novas experimentações políticas e de luta política." (p. 316).

Como de praxe entre as obras de Marcelo Lopes de Souza, o livro objeto desta resenha possui não apenas elevada densidade teórica, manifestada na riqueza conceitual e na amplitude e qualidade das referências bibliográficas apresentadas, mas também precisão terminológica e rigor estilístico - e, sobretudo, inúmeras ponderações e provocações que instigam a imaginação dos leitores.
Considerando que o capítulo 4 apresenta um escopo metodológico, a única ressalva a ser feita se refere à ausência de exemplos concretos que pudessem ilustrar as matrizes apresentadas nas figuras 18 e 21, assim como a tabela da figura 19. Mesmo que um exemplo concreto não coubesse no corpo do capítulo, ele poderia vir, talvez, como um anexo, facilitando ao leitor, especialmente ao estudante de graduação, o entendimento da proposta metodológica, que é rica e de suma importância. Outro pequeno detalhe, que poderia deixar mais claras ao leitor as ideias do autor, diz respeito à falta de legenda dos símbolos utilizados nas figuras 22, 24, 25 e 26. Ainda que sejam, em larga medida, autoexplicativos, nunca é demais evidenciar certas coisas, para evitar qualquer dificuldade de compreensão. Os leitores, especialmente os mais jovens, decerto agradeceriam. Apesar disso, os esquemas gráficos (em forma de figuras) apresentados em todo o livro facilitam a compreensão do que é explanado em forma de texto. São ferramentas didáticas que auxiliam no entendimento de temas complexos e instigantes, que são abordados de forma bastante clara no livro. 


\section{Referências}

ALIMONDA, Hector; PÉREZ, Catalina; MARTíN, Facundo (orgs.). Ecología política latinoamericana: Pensamiento crítico, diferencia latinoamericana y rearticulación epistémica. CLACSO; México/Ciccus. Vol. I, $2017 a$.

ALIMONDA, Hector; PÉREZ, Catalina; MARTíN, Facundo (orgs.). Ecología política latinoamericana: Pensamiento crítico, diferencia latinoamericana y rearticulación epistémica. CLACSO; México/Ciccus. Vol. II, 2017b.

SOUZA, Marcelo L. de. From the "right to the city" to the right to the planet: Reinterpreting our contemporary challenges for socio-spatial development. City, v. 19, $\mathrm{n}^{\circ}$ 4, pp. 408-443, 2015.

SOUZA, Marcelo L. de. O que é a Geografia Ambiental? AMBIENTES: Revista de Geografia e Ecologia Política, v. 1, $n^{\circ}$ 1, pp. 14-37, $2019 a$.

SOUZA, Marcelo L. de. Decolonising postcolonial thinking: ethnocentrism and sociocentrism as transideological and multiscalar phenomena. ACME: An International Journal for Critical Geographies, v. 18, $n^{\circ} 1$, pp. 1-24, $2019 \mathrm{~b}$.

SOUZA, Marcelo L. de. Right to the city or to the planet? Why Henri Lefebvre's vision is useful and too narrow at the same time. In: LEARY-OWHIN, Michel E. e MCCARTHY, John P. (orgs.): The Routledge Handbook of Henri Lefebvre, the City and Urban Society. Abingdon e Nova lorque: Routledge, 2019c.

Luciano Zanetti Pessôa Candiotto é Professor do Programa de Pós-graduação em Geografia da Universidade Estadual do Oeste do Paraná (UNIOESTE), Campus de Francisco Beltrão. E-mail: luciano.candiotto@unioeste.br 